\title{
Sedative Effects of Inhaled Benzylacetone and Structural Features Contributing to Its Activity
}

\author{
Takashi Miyoshi, ${ }^{a}$ Michiho Ito, ${ }^{* a}$ Takashi Kitayama, ${ }^{b}$ Sachiko Isomori, ${ }^{b}$ and \\ Fumiyoshi Yamashita ${ }^{c}$ \\ ${ }^{a}$ Department of Pharmacognosy, Graduate School of Pharmaceutical Sciences, Kyoto University: ${ }^{c}$ Department of \\ Drug Delivery Research, Graduate School of Pharmaceutical Sciences, Kyoto University; 46-29 Yoshida-Shimo- \\ Adachi-cho, Sakyo-ku, Kyoto 606-8501, Japan: and ${ }^{b}$ Department of Advanced Bioscience, Graduate School of \\ Agriculture, Kinki University; 3327-204 Nakamachi, Nara 631-8505, Japan.
}

Received March 30, 2013; accepted June 12, 2013

Benzylacetone is released by heated agarwood, when inhaled it has a potent effect on reducing the locomotor activity of mice. This study investigated the relationships between the sedative activities of benzylacetone and its derivatives as well as the chemical structures of these compounds by comparing their activities in mice treated with a series of compounds. It was demonstrated that benzylacetone-like compounds had sedative activities and their intensities varied depending on the functional group in the carbon chain, the substituent in the benzene ring, and their combinations. A quantitative structure-activity relationship study was carried out using a series of 17 benzylacetone derivatives to determine the structural features with significant for the sedative activity.

Key words benzylacetone; sedative effect; inhalation; structure-activity relationship; fuzzy adaptive least square

Agarwood (Jinkoh) is the resinous tree trunk from Aquilaria species, which is used as an herbal medicine in Kampo formulas as well as in traditional herbal prescriptions. It is also used in Kodo (Japanese incense ceremony) because of the fragrance it releases on heating. The aromatic components of agarwood comprise sesquiterpenes, chromone derivatives, and low-molecular weight aromatic compounds. ${ }^{1)}$ Benzylacetone (Fig. 1(1)), one of the low-molecular weight aromatic compounds, is abundant in the fragrance of the heated agarwood, but is not present in the wood and oil. ${ }^{2)}$ This compound is a potent inhibitor of locomotor activity in mice after its inhalation. ${ }^{3)}$ The smell of incense has traditionally been associated with this sedative effect. Research on the sedative effects of benzylacetone may provide scientific insights into the tradi-<smiles>CCCCCc1ccccc1</smiles>

(1)<smiles>COC(C)CCc1ccccc1</smiles>

(7)<smiles>CCCCc1ccc(O)cc1</smiles>

(13)<smiles>CCCCc1ccccc1</smiles>

(2)<smiles>CCCC(=O)Cc1ccccc1</smiles>

(3) tional Japanese culture of "listening to incense."

The relaxing effects of fragrances have been used in aromatherapy and other healthcare activities. It has been recently reported that odorants can be used in therapies to treat anxiety or dementia. ${ }^{45}$ Because the effects and applications of these therapies have received much attention, the pharmacological effects and their mechanisms of the action was studied. However, several relationships between chemical structures and pharmacological effects remain unknown.

The structure of benzylacetone is simple, one benzene ring with one saturated carbon chain and one functional group. However, it is assumed that only a few features are essential for hypolocomotion effects of benzylacetone. In this paper, we investigated the relationships between the sedative activities<smiles>CCCC(=O)c1ccccc1</smiles>

(4)<smiles>CC(O)CCc1ccccc1</smiles>

(5)<smiles>CC(C)CCc1ccccc1</smiles>

(6)<smiles>CC(O)CCc1ccccc1</smiles>

(8)<smiles>CC(C)CCc1ccccc1</smiles>

(9)<smiles>CC(=O)CCc1ccc(O)cc1</smiles>

(10)<smiles>COc1ccc(CCC(C)=O)cc1</smiles>

(11)<smiles>COc1ccc(CCC(C)=O)cc1</smiles>

(12)

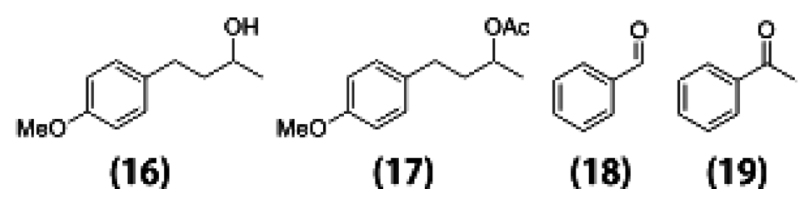

Fig. 1. Chemical Structures of Compounds Examined in the Study

1: 4-Phenyl-2-butanone (benzylacetone); 2: butylbenzene; 3: 1-phenyl-2-butanone; 4: 1-phenyl-1-butanone (butyrophenone); 5: 4-phenyl-2-butanol; 6: (3-methylbutyl)benzene; 7: 4-phenyl-2-butyl acetate; 8: $(S)$-4-phenyl-2-butanol; 9: $(R)$-4-phenyl-2-butanol; 10: 4-(4'-hydroxyphenyl)-2-butanone (raspberry ketone); 11: 4-(4'-methoxyphenyl)2-butanone (anisyl acetone); 12: 4-(4'-acetoxyphenyl)-2-butanone; 13: 4-butylphenol; 14: 4-(4'-hydroxyphenyl)-2-butanol; 15: 4-(4'-hydroxyphenyl)-2-butyl acetate; 16: 4-(4'-methoxyphenyl)-2-butanol; 17: 4-(4'-methoxyphenyl)-2-butyl acetate; 18: benzenecarbaldehyde (benzaldehyde); 19: 1-phenylethanone (acetophenone).

The authors declare no conflict of interest

* To whom correspondence should be addressed. e-mail: michihoi@pharm.kyoto-u.ac.jp 
of benzylacetone and its derivatives as well as the chemical structures of the compounds, by comparing their activities in mice treated with a series of compounds. The compounds examined in this study are derivatives of benzylacetone, where the ketone group was replaced by other functional groups, i.e., structural isomers, and derivatives with substituted groups on the benzene ring. A quantitative structure-activity relationship (QSAR) study was performed using a series of 17 benzylacetone derivatives to determine the structural features that are crucial for sedative activity.

\section{MATERIALS AND METHODS}

Figure 1 illustrates the compounds investigated in this study. Compounds (5), (7), (10), (11), (12), (14), (15), (16), and (17) were synthesized chemically. Triethyl citrate, an odorless solvent, and benzaldehyde (9) were purchased from Merck KGaA, Darmstadt, Germany and Wako Pure Chemical Industries, Ltd., Osaka, Japan, respectively. All other compounds were purchased from Tokyo Chemical Industry Co., Ltd., Tokyo, Japan. All the chemicals and reagents were of the highest available grade.

Animals The animal experiments were designed according to the recommendations of the Animal Research Committee of Kyoto University, Kyoto, Japan (the authorization numbers for the experiments were 2011-19 and 2012-18). Fourweek-old male ddY mice were purchased from Japan SLC Shizuoka (Shizuoka, Japan) and housed in colony cages at an ambient temperature of $25 \pm 2{ }^{\circ} \mathrm{C}$ with a 12 -h light-dark cycle. They were fed standard pellet chow and water ad libitum. All mice experiments were conducted between 10:00 and 17:00.

Methods The sedative activities of compounds were evaluated using mice and counting their spontaneous motor activity in an open-field test, as described in our previous report. ${ }^{3)}$ Each compound was completely dissolved in $400 \mu \mathrm{L}$ triethylcitrate and dropped onto four filter paper disks. The vapor from the solution pervaded a glass cage (W: $60 \mathrm{~cm} \times \mathrm{L}$ : $30 \mathrm{~cm} \times \mathrm{H}: 34 \mathrm{~cm}=$ volume: $0.065 \mathrm{~m}^{3}$ ) by natural diffusion. The total amount of the compound present in the cage was $4 \times 10^{-4}$, $4 \times 10^{-3}, 4 \times 10^{-2}, 4 \times 10^{-1}$, or $4 \mathrm{mg}$. The carbon numbers in some compounds differ from those in benzylacetone (1), the $\mathrm{w} / \mathrm{v}$ concentration of the solutions of the compounds administered to the mice were changed proportionally (Table 1), to ensure that the same number of molecules was administered in the samples.

Sixty minutes after charging the solution, a mouse was
Table 1. The W/V Concentration of the Solutions of the Compounds Administered to the Mice

\begin{tabular}{cc}
\hline \hline Compound & Total amount of compound present in the cage \\
\hline $\begin{array}{c}\text { (1) },(\mathbf{2}),(\mathbf{3}),(\mathbf{4}), \\
(\mathbf{5}),(\mathbf{6}),(\mathbf{8}),(\mathbf{9}),\end{array}$ & $4 \times 10^{-4}, 4 \times 10^{-3}, 4 \times 10^{-2}, 0.4 \mathrm{mg}$ \\
$(\mathbf{1 0}),(\mathbf{1 3}),(\mathbf{1 4})$ & \\
$(\mathbf{1 8})$ & $2.8 \times 10^{-4}, 2.8 \times 10^{-3}, 2.8 \times 10^{-2}, 0.28 \mathrm{mg}$ \\
$(\mathbf{1 9})$ & $3.6 \times 10^{-4}, 3.6 \times 10^{-3}, 3.6 \times 10^{-2}, 0.36 \mathrm{mg}$ \\
$(\mathbf{1 1}),(\mathbf{1 6})$ & $4.4 \times 10^{-4}, 4.4 \times 10^{-3}, 4.4 \times 10^{-2}, 0.44 \mathrm{mg}$ \\
$(\mathbf{7}),(\mathbf{1 2}),(\mathbf{1 5})$ & $4.8 \times 10^{-4}, 4.8 \times 10^{-3}, 4.8 \times 10^{-2}, 0.48 \mathrm{mg}$ \\
(17) & $5.2 \times 10^{-4}, 5.2 \times 10^{-3}, 5.2 \times 10^{-2}, 0.52 \mathrm{mg}$ \\
\hline
\end{tabular}

placed in the center of the cage and monitored with a video camera for $60 \mathrm{~min}$. The frequency of the mouse crossing lines drawn on the bottom of the cage at $10-\mathrm{cm}$ intervals was counted, and the area under the curve $(A U C)$ was calculated. Statistical analyses were performed with Dunnett's test using GraphPad Instat (GraphPad Software, San Diego, CA, U.S.A.). A probability level of $p<0.05$ was considered to be significant.

\section{RESULTS}

Effect of Presence of a Ketone Group on Sedative Activity Benzylacetone (1) and compound (2) were tested to determine their sedative activity in mice. Compound (2), which lacked a ketone group in its structure, had no significant effects at the range of appropriate concentrations. Benzylacetone (1) most significantly decreased the locomotor activity at a dose of $4 \times 10^{-4} \mathrm{mg}$, while a dose of $4 \times 10^{-3} \mathrm{mg}$ was also significantly effective (Fig. $2, p<0.01$ ). This result indicated that the ketone group on the carbon chain may have a significant effect on the sedative activity.

Relationship between the Position of a Ketone Group on the Carbon Chain and Sedative Activity Compounds (3) and (4) are structural isomers of benzylacetone (1). Compound (3) had no effect on the spontaneous locomotor activity of mice, whereas Compound (4) had significant effects at doses of $4 \times 10^{-1} \mathrm{mg}$ and $4 \times 10^{-3} \mathrm{mg}$ (Fig. 3). Compounds (2) and (3) reduced the locomotor activity at the same dose, i.e., $4 \times 10^{-1} \mathrm{mg}$ (Figs. 2b, 3a), but the activities of these compounds differed in the presence of a ketone group on the carbon chain. This result indicated that a ketone group on the C3 carbon neither contributed to nor inhibited the activity. Compounds with a ketone group on the carbon adjacent to $\mathrm{C} 3$ demonstrated the activity, suggesting that the ketone group
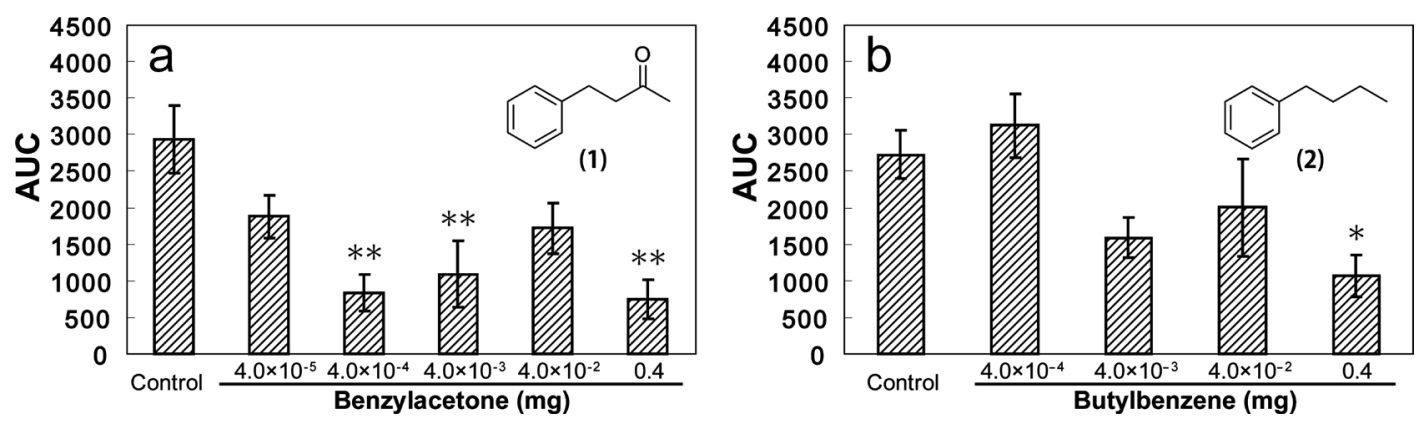

Fig. 2. Total Spontaneous Motor Activity of Mice Treated with Benzylacetone (1) and Butylbenzene (2)

Data are expressed as mean \pm S.E.M. for five mice. The statistical analysis was performed using one-way ANOVA followed by Dunnett's test. ${ }^{*} p<0.05$ and $* * p<0.01 v s$. control group. 

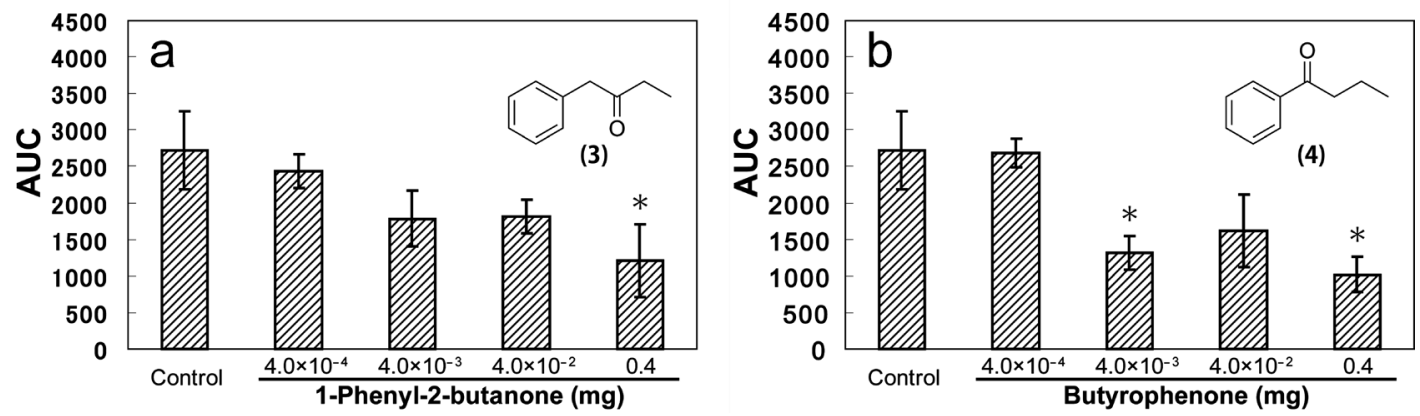

Fig. 3. Total Spontaneous Motor Activity of Mice Treated with 1-Phenyl-2-butanone (3) and Butyrophenone (4)

Data are expressed as mean \pm S.E.M. for five mice. Statistical analysis was performed using one-way ANOVA followed by Dunnett's test. * $p<0.05 v s$. control group.
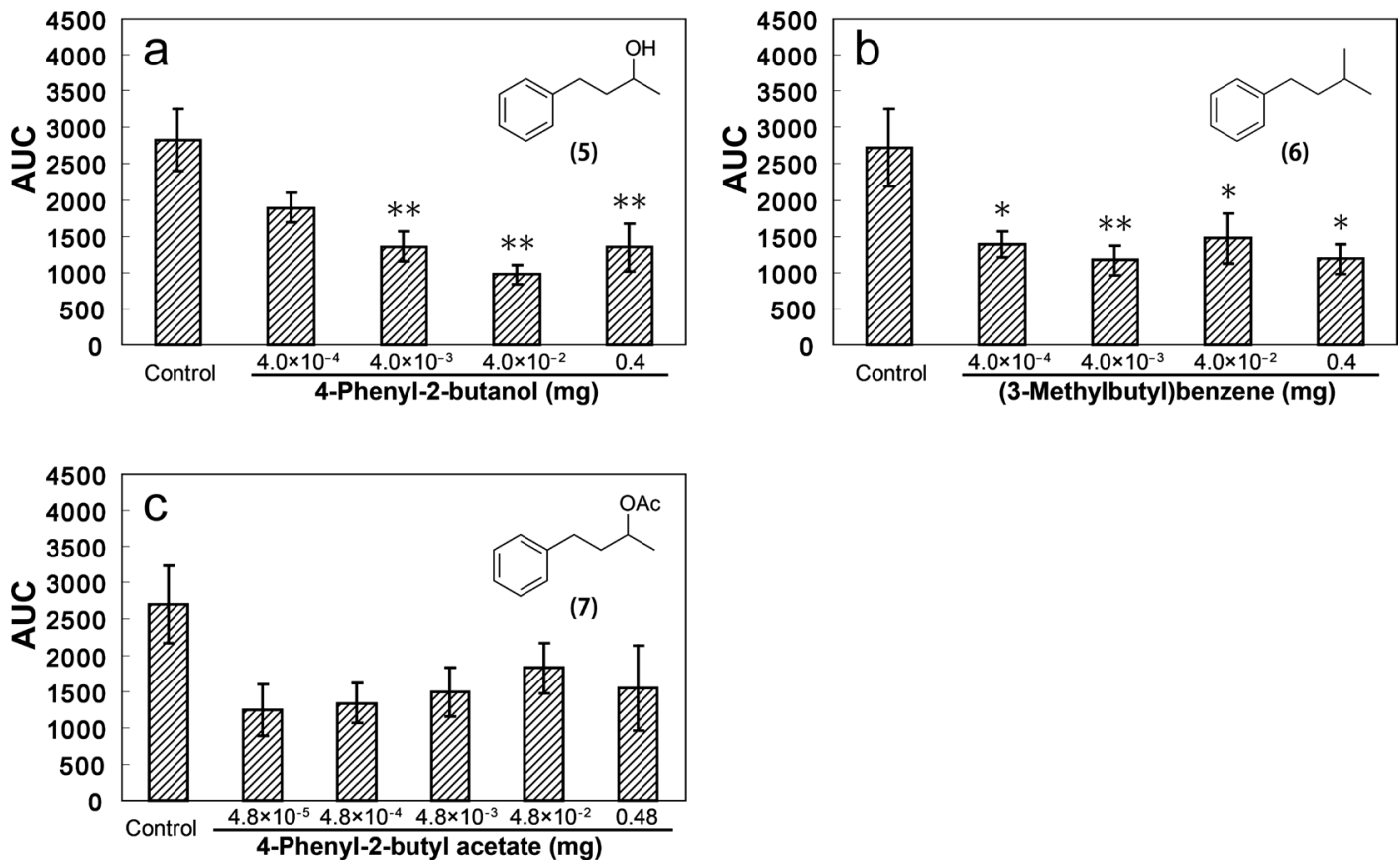

Fig. 4. Total Spontaneous Motor Activity of Mice Treated with 4-Phenyl-2-butanol (5), (3-Methylbutyl)benzene (6), and 4-Phenyl-2-butyl Acetate (7) Data are expressed as mean \pm S.E.M. for five mice. Statistical analysis was performed using one-way ANOVA followed by Dunnett's test. $* p<0.05$ and $* * p<0.01 v s$. control group.

position on the carbon chain significantly affected the activity.

Relationship between a Functional Group on the Carbon Chain and the Sedative Activity of Compounds Compound (5) had a hydroxyl group in the same position as the ketone group in benzylacetone (1), while (6) had a methyl group, and (7) had an acetoxy group. We evaluated the sedative activities of these three compounds. The sedative effects of Compounds (5) and (6) were strongest at doses of $4 \times 10^{-2} \mathrm{mg}$ and $4 \times 10^{-3} \mathrm{mg}$, respectively (Figs. $4 \mathrm{a}, \mathrm{b}$ ), which suggested that the effects of the methyl and hydroxyl groups were the same as that of the ketone group. Compound (7) had no significant effect (Fig. 4c). The substitution with the acetoxy group appeared to be more bulky than the ketone, hydroxyl, or methyl groups, so the size of the functional group on C2 may affect the sedative activity of benzylacetone.

Relationship between Chirality of Functional Groups and Sedative Activity To evaluate the effect of chirality of functional groups in Compound (5), we tested the $(S)$-enantiomeric Compound (8) and the $(R)$-enantiomeric Compound
(9). For Compound (8), there was a reduction in the locomotor activity at doses of $0.4 \mathrm{mg}$ and $4 \times 10^{-2} \mathrm{mg}$, while (9) reduced locomotor activity at doses of $4 \times 10^{-2} \mathrm{mg}$ and $4 \times 10^{-4} \mathrm{mg}$ (Fig. $5, p<0.01)$.

Effect of Benzene Ring Structure on Sedative Activity Compound (11), a derivative of benzylacetone (1) with an extra methoxy group on the benzene ring, is a constituent of the smoke from heated agarwood. ${ }^{1)}$ To investigate the relationship between the structures of substituents on the benzene ring of (1) and the sedative effect, the sedative effects of Compounds (10), (11), and (12) were assayed. Compound (10) had no significant effect on the locomotor activity levels of mice. The most statistically significant doses of Compounds (11) and (12) were $4.4 \times 10^{-2} \mathrm{mg}$ and $4.8 \times 10^{-4} \mathrm{mg}$, respectively (Fig. 6). These results suggested that the substituted groups on the benzene ring affected sedative activity.

Effect of Combinations of Substituents on the Carbon Chain and the Benzene Ring on Sedative Activity Compounds (13), (14), and (15) contain phenolic hydroxyl groups 

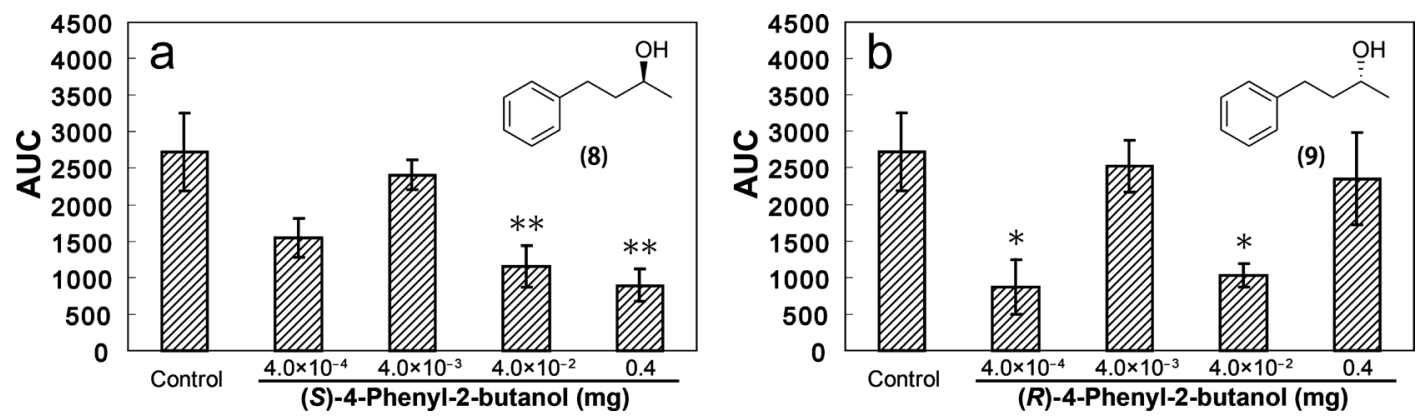

Fig. 5. Total Spontaneous Motor Activity of Mice Treated with (S)-4-Phenyl-2-butanol (8) and (R)-4-Phenyl-2-butanol (9)

Data are expressed as mean \pm S.E.M. for five mice. Statistical analysis was performed using one-way ANOVA followed by Dunnett's test. ${ }^{*} p<0.05$ and ${ }^{* *} p<0.01 v s$. control group.
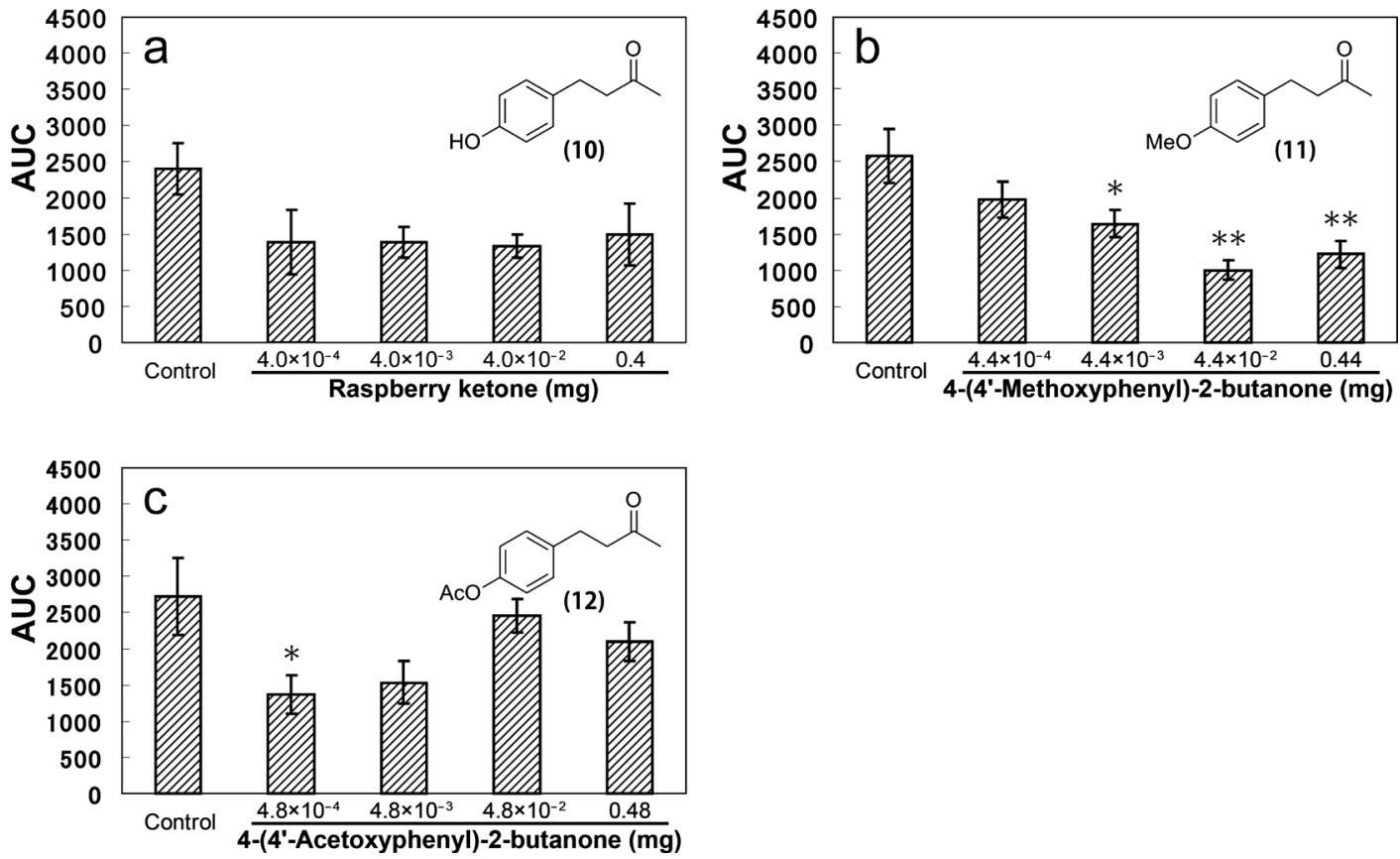

Fig. 6. Total Spontaneous Motor Activity of Mice Treated with Raspberry Ketone (10), 4-(4'-Methoxyphenyl)-2-butanone (11), and 4-(4'-Acetoxyphenyl)-2-butanone (12)

Data are expressed as mean \pm S.E.M. for five mice. Statistical analysis was performed using one-way ANOVA followed by Dunnett's test. ${ }^{*} p<0.05$ and ${ }^{* *} p<0.01 v s$. control group.

in their structures, while (16) and (17) contain methoxy groups on the benzene ring. Compounds (13) and (14) had sedative effects at doses of $4.0 \mathrm{mg}$ and $4 \times 10^{-3} \mathrm{mg}$, respectively. With Compound (15), a significant reduction in the locomotor activity was not observed (Figs. 7a, b, c). These results demonstrate that the combination of a phenolic hydroxyl group with a ketone group on the carbon chain reduces the activity, whereas a hydroxyl group on the carbon chain with a phenolic hydroxyl group enhances the activity. Given that there was no difference in the activity levels of Compounds (2) and (13), which have no substituents on the carbon chain, it is indicated that the combination of a phenolic hydroxyl group with substituents on the carbon chain modified the pharmacological effects. The sedative effect of Compound (16) was strongest at a dose of $0.44 \mathrm{mg}$. Compound (17) had its most significant effect at a dose of $5.2 \times 10^{-2} \mathrm{mg}$ (Figs. 7d, e).

Relationship between the Side-Chain Lengths of Compounds and Their Sedative Activity Compounds (18) and (19), which are derivatives of (4), have been detected in the smoke released by heated agarwood.) The sedative effects of (18) and (19) were strongest at doses of $2.8 \times 10^{-5} \mathrm{mg}$ and $3.2 \times 10^{-6} \mathrm{mg}$, respectively (Fig. 8).

Results and Discussion of the Locomotor Activity Transitions Compound (3), the counts per $5 \mathrm{~min}$ did not drop to zero until the end of the observation period with a dose of $4 \times 10^{-1} \mathrm{mg}$, producing the most significant activity (Fig. 9a). The total $A U C$ for the locomotor activity of mice treated with raspberry ketone (10) did not significantly decrease, although it was significantly suppressed at $5 \mathrm{~min}$ after beginning the observations. Some mice that were administered Compound (10) ceased their motion immediately after the test began and stood in place for $>5 \mathrm{~min}$ (Fig. 9b). With the exceptions of Compounds (3) and (10), locomotor activities of mice generally decreased to approximately zero, $35 \mathrm{~min}$ after administration of sedative compounds at most effective doses. Figure 9c shows an example of the locomotor activity transition with benzylacetone (1).

QSAR Model A QSAR study was performed to inves- 

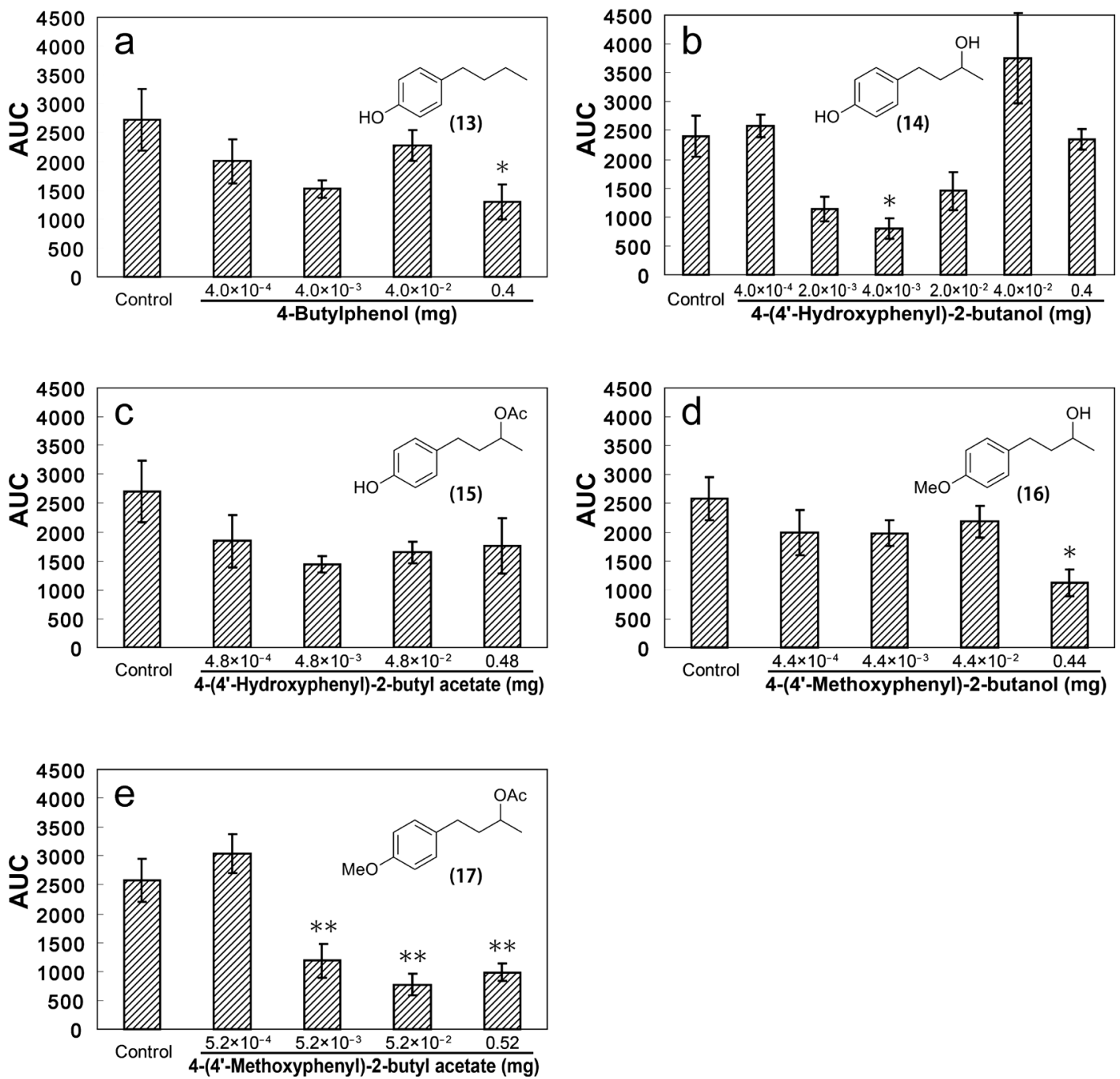

Fig. 7. Total Spontaneous Motor Activity of Mice Treated with 4-Butylphenol (13), 4-(4'-Hydroxyphenyl)-2-butanol (14), 4-(4'-Hydroxyphenyl)2-butyl Acetate (15), 4-(4'-Methoxyphenyl)-2-butanol (16), and 4-(4'-Methoxyphenyl)-2-butyl Acetate (17)

Data are expressed as mean \pm S.E.M. for five mice. Statistical analysis was performed using one-way ANOVA followed by Dunnett's test. ${ }^{*} p<0.05$ and ${ }^{* *} p<0.01 v s$. control group.
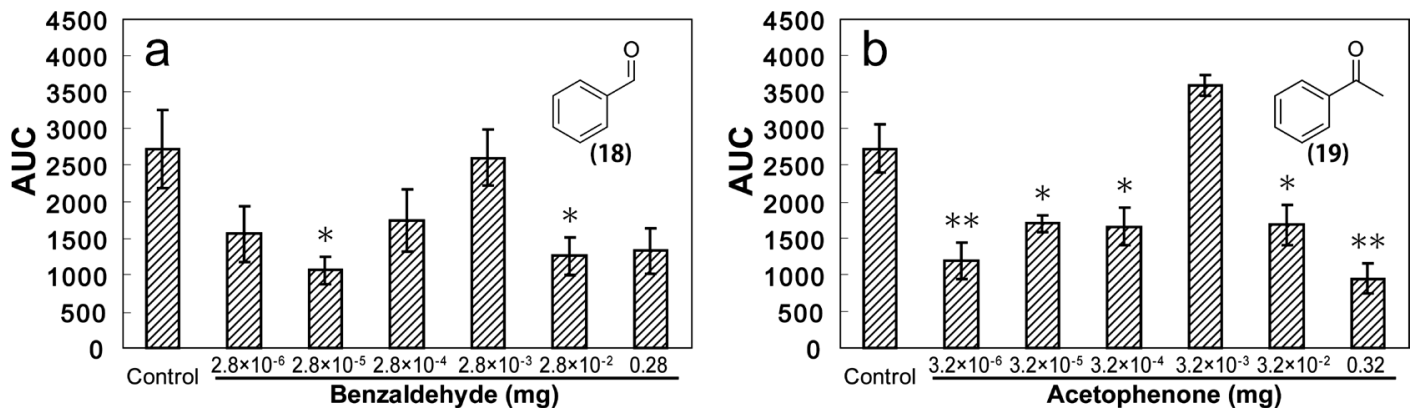

Fig. 8. Total Spontaneous Motor Activity of Mice Treated with Benzaldehyde (18) and Acetophenone (19) Data Are Expressed as Mean \pm S.E.M. for Five Mice

Statistical analysis was performed using one-way ANOVA followed by Dunnett's test. ${ }^{*} p<0.05$ and ${ }^{* *} p<0.01 v s$. control group.

tigate the relationship between the structure and activity of benzylacetone-like compounds. ${ }^{6}$. Because the experimental data were ordered, categorical variables, the fuzzy adaptive least squares (FALS) method was employed. ${ }^{7,8)}$ FALS method was developed as a pattern recognition method for correlating structure and activity ratings. With the exceptions of (8) and
(9), the compounds in Fig. 1 were rated at their most effective doses. We used the FALS method to derive a satisfactory Eq. 1 that successfully recognized 13 of the 17 compounds.

$$
\begin{aligned}
Z= & 4.362-0.761 E(x)-1.815(x)+0.273[L(x)]^{2} \\
& +27.233 C(x) \quad(n=17)
\end{aligned}
$$



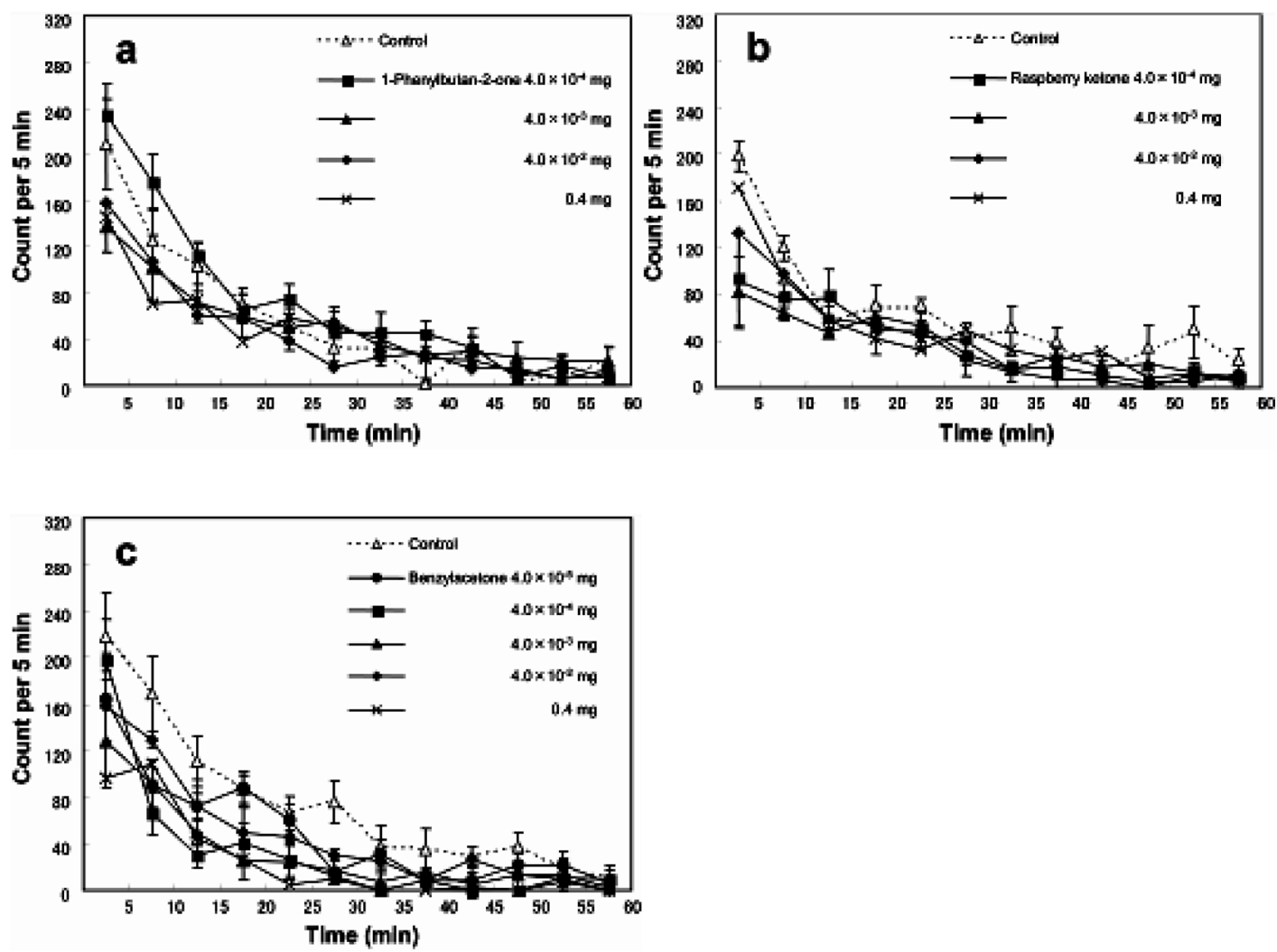

Fig. 9. Locomotor Activity Transitions of Mice Administered 1-Phenyl-2-butanone (3), Raspberry Ketone (10), and Benzylacetone (1)

Data are expressed as mean \pm S.E.M. for five mice.

Table 2. Descriptions and Ranks of the 17 Compounds Based on Results of Eq. 1

\begin{tabular}{|c|c|c|c|c|c|c|}
\hline \multirow{2}{*}{ Compound } & \multirow{2}{*}{$E(x)$} & \multirow{2}{*}{$L(x)$} & \multirow{2}{*}{$C(x)$} & \multirow{2}{*}{ Observed activity } & \multicolumn{2}{|c|}{ Calculated activity using Eq. } \\
\hline & & & & & MG & Rating \\
\hline 1 & 1.42 & 1.96 & -0.0515 & 4 & 0.003029 & 2 \\
\hline 2 & 0 & 4.01 & -0.0511 & 2 & 0.567624 & 2 \\
\hline 3 & 1.42 & 1.96 & -0.0541 & 2 & 0.993658 & 2 \\
\hline 4 & 1.42 & 2.66 & 0.0130 & 3 & 0.950615 & 3 \\
\hline 5 & 0.36 & 2.48 & -0.0531 & 2 & 0.973699 & 2 \\
\hline 6 & 0 & 4.43 & -0.0532 & 3 & 0.743772 & 3 \\
\hline 7 & 1.45 & 3.48 & -0.0531 & 1 & 0.782003 & 1 \\
\hline 10 & 1.38 & 1.48 & -0.0485 & 1 & 0.013494 & 2 \\
\hline 11 & 1.44 & 2.04 & -0.0507 & 2 & 0.996467 & 2 \\
\hline 12 & 1.4 & 1.56 & 0.0244 & 4 & 0.154391 & 5 \\
\hline 13 & 0.39 & 3.53 & -0.0484 & 2 & 0.996018 & 2 \\
\hline 14 & 0.38 & 2 & -0.0501 & 3 & 0.611677 & 3 \\
\hline 15 & 1.42 & 3 & -0.0501 & 1 & 0.520103 & 1 \\
\hline 16 & 0.36 & 2.56 & -0.0502 & 2 & 0.944605 & 2 \\
\hline 17 & 1.46 & 3.56 & -0.0524 & 2 & 0.303277 & 1 \\
\hline 18 & 1.24 & 1.71 & 0.0214 & 5 & 0.835083 & 5 \\
\hline 19 & 1.32 & 1.67 & 0.0166 & 5 & 0.517876 & 5 \\
\hline
\end{tabular}

MG: Membership grade. $E(x), L(x)$, and $C(x)$ were calculated using ADMET, EPI SUITE, and Chem 3D, respectively.

$E(x)$ : Maximum sigma Fukui index ${ }^{9}$ based on the oxygen atom

$L(x): \log P$ (KOWWIN v1.68 estimate)

$C(x)$ : Average charges of carbon atoms in the benzene ring at the ortho position in the carbon chain.
Table 2 illustrates descriptions of each compound. The membership grade indicates the degree to which the results of Eq. 1 belong in each cluster. The mean membership grade value was 0.642 . Spearman's rank correlation coefficient, ${ }^{10}$ which indicates the correlation between the observed activities and calculated activities using Eq. 1, was 0.873 . 


\section{DISCUSSION}

Sedative effects of active compounds used in this study were not dose-dependent. $A U C$ of the graph was lowest at a certain dose, and higher than that in both lesser and higher doses. Behavior of mice treated with lower dose than the most effective dose seemed as same as that of control group, while those administrated higher doses showed irregular behaviors such as frequent rearing and jumping. Abnormal behaviors observed in higher-dose cases resulted in larger $A U C$. As a result, an activity curve shown by $A U C$ often draws $\mathrm{U}$-curve, and which in common with other sedative volatile compounds. ${ }^{11,12)}$

We compared a series of benzylacetone isomers $\left(\mathrm{C}_{10} \mathrm{H}_{12} \mathrm{O}\right)$, i.e., Compounds (1), (3), and (4), which differed with respect to the ketone group position, to determine their sedative activities, and the rank order of the sedative effect was: (1) $>(4)>(3)$. The result revealed that the favorable ketone group positions for the sedative activity were in the order: $\mathrm{C} 2$, $\mathrm{C} 4$, and $\mathrm{C} 3$. It has been reported that aromatic compounds with isomeric structures may activate the rat olfactory bulb and produce similar patterns. ${ }^{13)}$ Therefore, the experimental results reported here, which suggested that structural isomers of benzylacetone (1) had different sedative activity levels, may indicate that a route other than the olfactory bulb may be relevant to the pharmacological effects of benzylacetone (1).

Previous reports have demonstrated that the chirality of some odor compounds such as linalool and carvone may produce different pharmacological effects. ${ }^{14,15)}$ A comparison of the activities of Compounds (5), (8), and (9) indicated that the chirality of the hydroxyl group in Compound (5) affected its activity. This may have been attributable to different steric configurations of the oxygen atom. The ketone group position on the carbon chain significantly affected the sedative activity. Furthermore, the sedative activity of benzylacetone-like compounds appeared to be affected by the position of the oxygen atoms. However, Compound (6), which did not include oxygen atoms in its structure, has the same effect as that of (1) or (5), which suggested that other factors affected the sedative effect in addition to oxygen atoms. Both enantiomers of Compound (5) had sedative effects at a dose of $4 \times 10^{-2} \mathrm{mg}$, which was the most effective dose for Compound (5). This may mean that the effects of the two enantiomers were additively enhanced by the administration of a racemic compound at a dose of $4 \times 10^{-4} \mathrm{mg}$. However, at a dose of $4 \times 10^{-3} \mathrm{mg},(8)$ and (9) did not decrease the locomotor activity significantly. The relationships among the activities of Compounds (5), (8), and (9) could not be determined based on the results of the present study; thus, further studies are necessary.

A comparison of the sedative activities of Compounds (7) and (1) revealed that the methoxy group appeared to enhance their activity, whereas in (5) and (16) it reduced their activity. This suggested that the combination of the methoxy group attached to the benzene ring and the substituents on the carbon chain can alter the pharmacological effects of benzylacetone derivatives.

Compounds (4), (18), and (19) share a common chemical structure, which is the same as the structure of (18), which may contribute to their activity. However, when the strength of their effects was compared, it appeared that the side-chain length may have some effects on the activity.
Concentrations of compounds in the air administered to the mice in our experiments were measured in several ways: gas in the glass cage was collected and absorbed to solvent, or flitter papers were extracted by solvents after experiments to measure amount of compounds remaining in the paper. However, the compounds could not be measured accurately because the levels of the compounds in the air were too low to be detected using a gas chromatography equipped with frame ionization detecter (GC-FID) instrument. The peak areas of the charts in the solid phase microextraction (SPME)-GC analyses appeared to be correlated with the concentrations of administrated samples; however, the SPME method is not well validated and further investigation is required.

The locomotor activity transitions of mice treated with (3) and (10) differed from those of other compounds, so these two compounds may have unique mechanisms of action. The counts were significantly low, particularly at the beginning of the testing period with Compound (10), which may indicate that (10) had muscle-relaxing or acute tranquilizing effects.

In QSAR study, the relative contribution ratio of the sedative activity parameters was assessed based on the product of absolute values of standard deviations and coefficients using Eq. 1. The contribution of $L(x)(\log P)$ and its squared term was $62.6 \%$, indicating that $\log P$ of the benzylacetone derivatives affect their sedative effects greatly. The $\log P$ values of Compounds (1) and (14), which had sedative activities, were 1.96 and 2.00, respectively and those of Compounds (5) and (10), which had no sedative effects, were 2.48 and 1.48 (Table $2)$, respectively. The $\log P$ values of highly active compounds such as (1), (18), and (19) were approximately 2, demonstrating that the compounds were more potent when their $\log P$ values were close to 2 in this study. The $\log P$ values as well as the sedative effects of compounds were significantly affected by the presence of a hydroxyl group in the structure.

In general, the activities of highly lipophilic or hydrophilic compounds are comparatively low. ${ }^{16)}$ The coefficient of the squared term of $\log P$ in Eq. 1 was positive, which suggests that the relationship between the sedative activity and $\log P$ of benzylacetone derivatives was exceptional. The mechanisms of pharmacological effects of fragrant compounds are believed to involve two routes: one via the blood stream and another via the olfactory bulb. ${ }^{17)}$ These two routes may include several biological membranes that fragrant compounds may pass through and several sites of action, so multiple combinations of these will produce an unusual coefficient of $\log P$.

The relative contribution ratio of $C(x)$ was $24.5 \%$, which indicated that the ketone group at benzyl position, such as that in (4), may have affected the charge on the benzene ring and resulted in a change in the activity. The contribution of $E(x)$ to Eq. 1 was $12.9 \%$. This suggests that the charges of oxygen atoms affected the activity of the compounds. If the charges of oxygen atoms are important for the binding of compounds to the site of action, the different sedative activities of Compounds (8) and (9), two isomers with different hydroxyl group chirality, could be well postulated.

\section{CONCLUSION}

This study demonstrated that benzylacetone-like compounds had a sedative activity that varied according to the functional group on the carbon chain, the substituent on the 
benzene ring, and their combinations. A comparison of the pharmacological effects of Compounds (8) and (9) showed that the chirality of a functional group affected the sedative activity. These relationships between the chemical structure and pharmacological activity will aid in designing useful compounds such as fragrances with sedative effects.

QSAR analysis demonstrated that the rank order of the activities of compounds could be determined using an equation that calculated the $\log P$ values, the charge distribution of the benzene ring, and the charge of oxygen atoms on the carbon chain. Several compounds isolated from plants have been reported to demonstrate sedative effects when inhaled, and their pharmacological effects have been evaluated. However, the relationship between the chemical structure and sedative activity of natural sedative compounds based on their degree of potency, have not been reported till date. Our QSAR analysis using the FALS method will facilitate broader applications of aroma compounds for practical use.

The compounds described in this report, i.e., benzylacetone (1), anisyl acetone (11), acetophenone (16), and benzaldehyde (17) have been found in the smoke released by heated agarwood. ${ }^{1)}$ With the exception of (11), it is assumed that these compounds are generated from odorless compounds present in agarwood, and chromone derivatives are possible candidates for their precursors. ${ }^{18-20)}$ These compounds were shown to be potent sedatives in this study, the psychological calming effect may be the reason for using agarwood traditionally. The present study identified some key chemical structure features that contribute to benzylacetone activity. Further studies on the structure-effect relationship that underpins the sedative activities of volatile compounds may facilitate the practical application of fragrant natural medicines such as agarwood in treatment of several diseases.

\section{REFERENCES}

1) Regula N. The volatile and semi-volatile constituents of agarwood, the infected heartwood of Aquilaria species: A review. Flavour Fragrance J., 26, 73-89 (2011).

2) Ishihara M, Tsuneya $T$, Uneyama $K$, Ishihara $M$, Tsuneya $T$, Uneyama K. Components of the agarwood smoke on heating. J. Essent. Oil Res, 5, 419-423 (1993).

3) Takemoto H, Ito M, Shiraki T, Yagura T, Honda G. Sedative effects of vapor inhalation of agarwood oil and spikenard extract and identification of their active components. J. Nat. Med., 62, 41-46 (2008).

4) Lee YL, Wu Y, Tsang HW, Leung AY, Cheung WM. A systematic review on the anxiolytic effects of aromatherapy in people with anxiety symptoms. J. Altern. Complement. Med., 17, 101-108 (2011).

5) Fung JKK, Tsang HW, Chung RC. A systematic review of the use of aromatherapy in treatment of behavioral problems in dementia. Geriatr. Gerontol. Int., 12, 372-382 (2012).

6) Hansch C, Fujita T. $p-\sigma-\pi$ analysis. A method for the correlation of biological activity and chemical structure. J. Am. Chem. Soc., 86, 1616-1626 (1964).

7) Moriguchi I, Hirono S, Liu QA, Matsushita Y, Nakagawa T. Fuzzy adaptive least squares and its use in quantitative structure-activity relationships. Chem. Pharm. Bull., 38, 3373-3379 (1990).

8) Moriguchi I, Hirano H, Hirono S. Prediction of the rodent carcinogenicity of organic compounds from their chemical structures using the FALS method. Environ. Health Perspect., 104 (Suppl. 5), 1051-1058 (1996).

9) Bultinck P, Carbó-Dorca R, Langenaeker W. Negative Fukui functions: New insights based on electronegativity equalization. $J$. Chem. Phys., 118, 4349 (2002).

10) Spearman C. The proof and measurement of association between two things. Am. J. Psychol., 100, 441-471 (1987).

11) Takemoto $\mathrm{H}$, Yagura $\mathrm{T}$, Ito $\mathrm{M}$. Evaluation of volatile components from spikenard: valerena-4,7(11)-diene is a highly active sedative compound. J. Nat. Med., 63, 380-385 (2009).

12) Ito K, Ito M. Sedative effects of vapor inhalation of the essential oil of Microtoena patchoulii and its related compounds. J. Nat. Med., 65, 336-343 (2011).

13) Farahbod H, Johnson BA, Minami SS, Leon M. Chemotopic representations of aromatic odorants in the rat olfactory bulb. J. Comp. Neurol., 497, 350-366 (2006).

14) Höferl M, Krist S, Buchbauer G. Chirality influences the effects of linalool on physiological parameters of stress. Planta Med., 72, 1188-1192 (2006).

15) de Sousa DP, de Farias Nóbrega FF, de Almeida RN. Influence of the chirality of $(R)-(-)$ - and $(S)-(+)$-carvone in the central nervous system: a comparative study. Chirality, 19, 264-268 (2007).

16) García-Sosa AT, Maran U, Hetényi C. Molecular property filters describing pharmacokinetics and drug binding. Curr. Med. Chem., 19, 1646-1662 (2012).

17) Takemoto H, Ito M, Akaike A, Kobayashi Y. Stress relief effects valerena-4,7(11)-diene. Annual Meeting of the Japanese Society of Pharmacognosy, Abstracts Papers, 130, 224 (2010).

18) Hashimoto K, Nakahara S, Inoue T, Sumida Y, Takahashi M, Masada Y. A new chromone from agarwood and pyrolysis products of chromone derivatives. Chem. Pharm. Bull., 33, 5088-5091 (1985).

19) Shimada Y, Tominaga $T$, Konishi $T$, Kiyosawa S. Studies on the agarwood (Jinko). I. Structures of 2-(2-phenylethyl)chromone derivatives. Chem. Pharm. Bull., 30, 3791-3795 (1982).

20) Yagura $T$, Ito $M$, Kiuchi $F$, Honda $G$, Shimada $Y$. Four new 2-(2-phenylethyl)chromone derivatives from withered wood of Aquilaria sinensis. Chem. Pharm. Bull., 51, 560-564 (2003). 